Jóvenes y adolescentes en la agenda de los medios gráficos de la norpatagonia Sandra Poliszuk

Apuntes de comunicación, educación y discurso (N. ${ }^{\circ}$ 2), e011, noviembre 2017

ISSN 2525-2046 | https://doi.org/10.24215/25252046e011

http://perio.unlp.edu.ar/ojs/index.php/apuntes

FPyCS | Universidad Nacional de La Plata

La Plata | Buenos Aires | Argentina

\title{
Jóvenes y adolescentes en la agenda de los medios gráficos de la norpatagonia
}

\author{
Young People and Adolescents \\ in the Graphic Media Agenda of Norpatagonia
}

\author{
Sandra Poliszuk \\ spoliszuk@yahoo.com \\ https://orcid.org/0000-0002-8989-7760 \\ Centro de Estudios y Análisis Político (CEAP) \\ Universidad Nacional del Comahue \\ Centro Interdisciplinario de Estudios sobre Derechos, Inclusión y Sociedad (CIEDIS) \\ Universidad Nacional de Río Negro \\ Argentina
}

\section{Resumen}

En el artículo la autora analiza la relevancia que tienen los jóvenes y los adolescentes en la cobertura informativa de dos diarios de la región norpatagónica de la Argentina, Noticias de la Costa y Río Negro. En el estudio se demuestra que, de un modo sesgado, la agenda de los medios gráficos locales los presenta vinculados, predominantemente, con acontecimientos delictivos o violentos $\mathrm{y}$, muy por debajo, con temáticas como educación, política, actividades recreativas, género y salud.

Palabras clave

jóvenes, medios gráficos, coberturas, norpatagonia

\section{Abstract}

In this article the authoress analyzes the relevance of young people and adolescents in the coverage of two newspapers in the North Patagonia region of Argentina, Noticias de la Costa y Río Negro. The study demonstrated that, in a biased way, the agenda of local graphic media presents them linked, predominantly, with criminal or violent events and, far below, with other topics such as: education, politics, recreational activities, gender and health.

Keywords

young people, media, media coverages, north Patagonia region 


\title{
Jóvenes y adolescentes en la agenda de los medios gráficos de la norpatagonia
}

\author{
Por Sandra Poliszuk
}

Entre 2015 y 2016 agregaciones estudiantiles de diferentes instituciones educativas de nivel medio y universitario llevaron a cabo distintas manifestaciones en las calles y otros espacios públicos en ciudades de la región norpatagónica y se convirtieron en actores protagonistas de las noticias locales. Los estudiantes tomaron la iniciativa de constituirse en fuente informativa y en protagonistas de las noticias. Para ello, se organizaron, planificaron sus intervenciones públicas e interactuaron con los medios locales.

Aunque, en general, no parecen interesados en interactuar con los medios tradicionales de la región y en incidir en los temas de sus agendas, en los últimos dos años emergieron diversas demandas y situaciones que convocaron a jóvenes y a adolescentes estudiantes a mostrarse en los espacios públicos, y a legitimar su voz y sus puntos de vista en las coberturas noticiosas.

Los medios gráficos de la región cubrieron los reclamos y las movilizaciones estudiantiles en forma acotada y episódica, es decir, circunscribieron su tratamiento a instancias concretas o a eventos definidos, sin mayor profundización y desde enfoques que destacan la voz de directivos, de funcionarios y de padres.

La cuestión juvenil aparece en la agenda de los medios gráficos regionales vinculada, principalmente, a otro tipo de acontecimientos: los hechos delictivos, en los que los jóvenes y los adolescentes se muestran como víctimas, como victimarios o actuando con violencia unos contra otros.

¿Qué dice y qué calla el tratamiento mediático de los acontecimientos en los cuales aparecen jóvenes y adolescentes involucrados? ¿Con qué otros temas y tópicos se asocian las coberturas noticiosas que los tienen como actores de las noticias?

El objetivo de este artículo es analizar la relevancia que tienen los jóvenes y los adolescentes en la cobertura noticiosa de dos diarios de la región norpatagónica de la Argentina, para luego centrarse en el estudio del tratamiento informativo de 
acontecimientos en los que aparecen involucrados como participantes de instituciones y políticas educativas, mediante un análisis que se sustenta en los aportes de las teorías de la agenda setting y del framing.

El trabajo socializa algunos resultados de un proyecto de investigación sobre políticas de visibilidad y agendas de lo juvenil en la ciudad de Viedma1. Dicha investigación busca conocer y comparar el lugar que ocupa la cuestión juvenil en la agenda de diarios de circulación regional, impresos y digitales, en la provincia de Río Negro, y analizar los encuadres noticiosos utilizados por dichos medios cuando los acontecimientos de sus coberturas noticiosas tienen a los jóvenes como protagonistas. Se propone, además, conocer la relación entre los encuadres periodísticos utilizados en los diarios y los discursos de las instituciones que trabajan con jóvenes y adolescentes en Viedma, y cómo estos encuadres son resignificados entre los jóvenes, integrantes de diversas agregaciones con protagonismo social, que intervienen como actores y como fuentes informativas en los acontecimientos narrados por los medios locales.

En el artículo se define, en primer lugar, la perspectiva teórica general de la investigación, sus principales nudos críticos y el enfoque conceptual sobre la relevancia mediática, dimensión abordada como primer objetivo del proyecto; en segundo lugar, se caracteriza brevemente el escenario sociopolítico y mediático de la ciudad de Viedma en el cual se inscribe el estudio; en tercer lugar, se expone la perspectiva metodológica y, por último, los resultados parciales del proceso investigativo y algunas reflexiones finales.

\section{La producción social de las juventudes y la producción mediática de la realidad}

Como punto de partida se asume que la producción de las juventudes como categoría social forma parte del complejo procesamiento de las diferencias en nuestras sociedades, donde entran en juego fuerzas enfrentadas por la definición de representaciones y de modelos de comprensión del mundo que sustentan la existencia social.

Un entramado de instituciones, de agencias y de actores sociales operan en la construcción de la cuestión juvenil y funcionan como productores de realidad y de políticas específicas. Así condensan los procesos de hegemonización político-cultural en un determinado momento histórico. 
Para comprender la manera en la que jóvenes y adolescentes viven sus experiencias de participación en el espacio público (cuestión abordada en investigaciones anteriores) es necesario identificar los discursos a partir de los cuales dichas experiencias se configuran. Uno de los supuestos del que parte este estudio es que las coberturas noticiosas realizadas por los medios de comunicación forman parte de complejas negociaciones, no exentas de tensiones y de conflictos, entre diversos actores e instituciones insertos en sistemas de poder, cuyas racionalidades afectan, de manera heterogénea, las propias prácticas de jóvenes y de adolescentes en el espacio público. La comprensión de la racionalidad mediática constituye un primer nivel de análisis, que debe ser redimensionado a la luz de sus interdependencias con discursos y con prácticas desplegadas en otros campos de acción donde jóvenes y adolescentes disputan los sentidos de sus prácticas políticas.

Las regulaciones de las que ha sido objeto la vida de jóvenes y de adolescentes se articulan con particulares condiciones materiales y simbólicas en las que confluyen diferentes fuerzas, dispositivos de poder-saber e imaginarios sociales. Los medios de comunicación son dispositivos de regulación cultural y producen y resignifican un entramado de discursos sociales que afecta sus condiciones de vida.

La cuestión juvenil ocupa, por momentos, un lugar de atención social y presenta un creciente peso en la agenda mediática y política, principalmente, cuando la narrativa noticiosa asume la lógica del espectáculo.

\section{¿Por qué un asunto social adquiere atención pública en un determinado momento?}

Desde la perspectiva constructivista, los asuntos o los problemas sociales no solo adquieren atención pública y preocupación social por sus condiciones objetivas, sino que son el fruto de procesos de definición colectiva, es decir, son construcciones sociales (Edelman, 1991). Tan solo algunos fenómenos sociales se constituyen, en momentos específicos, en causa de preocupación y pasan a ser considerados problemas sociales (Spector \& Kitsuse, [1977] 1987). La percepción pública de determinadas cuestiones que pueden concitar interés o atención en un determinado momento depende, en parte, de la relación entre la naturaleza de ciertos problemas y, fundamentalmente, del papel que asumen diversas organizaciones, grupos y actores colectivos (Tuñón, 2002) quienes, no solamente concitan interés al otorgarles relevancia sino, también, al definirlos mediante marcos interpretativos desde los cuales son conocidos públicamente. 
Sostiene Murray Edelman (1991) que la construcción de temas o de problemas sociales es un proceso complejo y sutil, una faceta de la formación convergente de la esfera social, integralmente vinculada con la interminable construcción y reconstrucción de las causas políticas, las estructuras de rol y las posturas morales. Por eso, está atravesada por conflictos y por pugnas en torno a la definición de marcos interpretativos desde los cuales comprender los fenómenos en los que distintas fuerzas sociales disputan su poder de visión y su clasificación de la realidad.

En ese entramado, los medios de comunicación funcionan como productores de realidad; no solamente distribuyen roles y asignan atributos socioculturales sino, y principalmente, definen problemáticas sociales y cartografían mapas sociales, contribuyendo a reforzar ciertos tópicos y a desechar otros del imaginario colectivo. La producción mediática de la realidad fortalece y legitima una política de visibilidad orientada al despliegue de modos desiguales de distribución y de asignación de atributos socioculturales (Aguilera, 2012).

\section{La relevancia informativa: aproximaciones teóricas}

Entre los interrogantes que sustentan el estudio destacamos: ¿Con qué temas y tópicos se asocian las coberturas noticiosas de acontecimientos que tienen a jóvenes y a adolescentes como protagonistas?, ¿qué jerarquía adquiere la cobertura mediática de esos acontecimientos en los diarios estudiados?, ¿desde qué enfoques se presentan las noticias?

Para aproximarnos a esta cuestión hemos realizado un primer estudio sobre la relevancia informativa. El abordaje de este aspecto ha sido fundamental para el desarrollo de las investigaciones sobre las agendas mediáticas y sobre los encuadres noticiosos, y forma parte de una de las vertientes del campo de los estudios sobre el vínculo entre agendas, medios de comunicación y opinión pública en constante crecimiento en las últimas cuatro décadas. Las teorías de la Agenda Setting y del Framing constituyen dos perspectivas diferenciales que configuran este campo, aunque con puntos de contacto y de diálogo.

Desde este campo, diversos estudios «coinciden en entender que un modo de encuadrar es atribuir relevancia a un tema, es decir, dar prioridad a unos elementos sobre otros y hacerlos más fáciles de recordar» (Aruguete \& Amadeo, 2012, p. 186). Para otorgar una relevancia determinada a las noticias, los periodistas se valen de encuadres en el texto. Lo hacen, principalmente, por medio de la repetición del tema y de la ubicación en la cual presentan la noticia. La relevancia es definida como la 
«visibilidad de la información a partir de su ubicación, su tamaño, su disposición con respecto a otro tipo de información o su mayor frecuencia de cobertura» (Amadeo, 2008, p. 8).

La teoría del Framing, también conocida como Teoría del Encuadre, estudia los principios organizativos, compartidos por la sociedad, en los procesos de construcción y de reconstrucción de los temas y los problemas sociales. El investigador Stephen Reese aportó una de las definiciones más completas de frame: «Son principios organizadores socialmente compartidos y persistentes en el tiempo, que trabajan simbólicamente para estructurar el mundo social de modo significativo» (citado en Aruguete \& Amadeo, 2012, p. 179).

Dentro de esta perspectiva teórica, Iyengar y Kinder plantean que «los medios de comunicación influyen en la percepción pública no tanto por el hecho de mencionar asuntos delicados, sino por la forma en la que se los presenta» (citado en Aruguete \& Amadeo, 2012, p. 178). Con la Teoría del Encuadre se puede comprender la conexión existente entre las narraciones noticiosas de los medios de comunicación y las interpretaciones sociales de esos discursos, que a su vez se configuran, de manera recíproca, a través de un proceso de reinterpretación permanente.

Natalia Aruguete (2011) destaca, a partir de una lectura de la propuesta teórica de Robert Entman (1993), que los frames son herramientas fundamentales para transmitir informaciones: aumentan las perspectivas, revelan entendimientos particulares sobre los eventos y terminan transformando la forma de pensar del público sobre un asunto. Siguiendo con su lectura, encuadrar es definir problemas: diagnosticar sus causas o las fuerzas que lo crean, hacer juicios morales al evaluar al agente que lo causa, medir con qué costos y beneficios, y sugerir soluciones, ofreciendo y justificando un tratamiento y prediciendo sus resultados. A partir de proveer, de repetir y de reforzar palabras o imágenes que se refieren a ciertas ideas pero no a otras, los frames funcionan para dar más relevancia a ciertas ideas en los textos, menos a algunas y para volver completamente invisibles otras (Aruguete, 2011).

\section{El escenario mediático en la ciudad de Viedma}

Viedma es una ciudad predominantemente administrativa y sede del poder político provincial. La presencia de la administración pública estructura su identidad y las relaciones sociales, en general. Aunque la actividad administrativa en la ciudad entró en 
un período de crisis desde mediados de la década de 1990, con los procesos de reforma estatal neoliberales, el empleo público siguió y sigue siendo la actividad ocupacional predominante.

En la ciudad funcionan más de 30 radios. Una gran mayoría se sustenta, principalmente, con publicidad oficial y no desarrolla producción periodística propia sino que reproduce los contenidos de agencias, de redes sociales, y del área de comunicación del gobierno y de la administración pública, provincial y municipal.

Uno de los principales diarios que circula en la ciudad es Noticias de la Costa, fundado en Viedma, en abril de 1996, por Horacio Massaccesi (exgobernador provincial y excandidato a presidente de la Nación) y por Patricia Querejeta. Este diario tiene alcance provincial aunque su mayor influencia abarca el sur bonaerense (Pedro Luro y Carmen de Patagones) y el este rionegrino (Viedma, Sierra Grande, San Antonio Oeste y Conesa, entre otros).

Hay una fuerte trama de relaciones entre medios, periodistas y estructura política. Las relaciones se organizan sobre la base de lazos verticales, de arreglos jerárquicos entre actores con un control diferencial sobre los principales recursos disponibles: los recursos del Estado.

Las decisiones políticas se concentran en el poder ejecutivo provincial que ejerce un fuerte control sobre el aparato de la administración y se hace extensivo a otros ámbitos, organizaciones e instituciones; entre ellas, los medios de comunicación. Estas características no excluyen distintas tensiones y conflictos entre grupos y facciones partidarias e individuos propietarios de medios, en distintas coyunturas políticas y sociales.

La ciudad cuenta, además, con una radio y un canal digital de televisión comunitarios: Radio Encuentro y ENTV Viedma, respectivamente, que integran la red del Foro Argentino de Radios Comunitarias (FARCO) y la Asociación Latinoamericana de Educación Radiofónica (ALER).

\section{Propuesta metodológica operativa}

La estrategia metodológica general que sustenta la investigación consiste en el despliegue de un abordaje mixto cuanti y cualitativo que se aplica sobre tres corpus: las coberturas mediáticas de acontecimientos que tengan a jóvenes y a adolescentes como 
protagonistas, los discursos de la Red Adolescencia Viedma, y los de jóvenes y adolescentes que participan en las instituciones y en las organizaciones agrupadas en la mencionada red.

Un primer objetivo específico de la investigación fue la relevancia que tienen jóvenes y adolescentes en la agenda de los diarios impresos Noticias de la Costa y Río Negro, publicaciones de referencia dominante en la ciudad de Viedma, durante tres meses de 2016. Abordamos la relevancia informativa, tal como se definió anteriormente, teniendo en cuenta dos factores. Por un lado, la frecuencia o la cantidad de menciones explícitas a jóvenes y a adolescentes en las piezas periodísticas publicadas en los diarios analizados. Por el otro, los mecanismos que los medios utilizan para darle importancia a un tema, la jerarquía o la prominencia que le otorgan en el tratamiento noticioso, es decir, la visibilidad de la información a partir de su ubicación, su tamaño o su disposición (Amadeo, 2008).

El tratamiento informativo que muestra a jóvenes y a adolescentes como actores de las noticias en los ambos diarios incluyó un total de 963 piezas periodísticas. Estas fueron publicadas en 138 ediciones ( 69 de cada periódico) entre el 23 de abril y el 30 de julio de 2016. El diario Noticias de la Costa publicó 332 piezas periodísticas en cuya cobertura noticiosa aparecen jóvenes y adolescentes involucrados como actores principales o secundarios, lo que comprende el 35\% del total de noticias. El diario Río Negro, en tanto, incluyó en su agenda 631 noticias sobre jóvenes y adolescentes en el período analizado, lo que comprende el $65 \%$ del corpus analizado hasta el momento.

Esta información muestra que el diario Río Negro publicó una mayor cantidad de piezas periodísticas que el diario Noticias de la Costa en las que se abordan acontecimientos que involucran a jóvenes y a adolescentes. Sin embargo, el análisis de esta variable de manera descontextualizada no permite concluir, a priori, que el diario que mayor cantidad de notas le dedica a jóvenes y aadolescentes es el que les otorga mayor importancia total.

Fue necesario establecer la frecuencia en función del hueco informativo de cada diario. Es decir, en relación con la cantidad total de espacio que se deja en todas las páginas del periódico una vez que se ha insertado la publicidad (McCombs, 2006). Por eso, se calculó el hueco informativo como el total de piezas textuales de cada diario al que se restaron la publicidad, los clasificados, los chistes, los entretenimientos y los suplementos especiales. No obstante, se incluyó el suplemento deportivo, espacio en el que con frecuencia aparecen referenciados temas y actores como «juveniles». 
Para calcular en cada periódico la porción del hueco informativo que ocuparon las noticias sobre jóvenes y adolescentes se contabilizó la totalidad de las noticias publicadas, independientemente de los temas a los que refirieran.

Durante los tres meses de relevamiento, el diario Noticias de la Costa editó un total de 3037 noticias, de las cuales 332 involucran a jóvenes y a adolescentes. Por lo tanto, el 9,95\% de su hueco informativo fue dedicado al tema de nuestra investigación. En el mismo lapso, Río Negro publicó un total de 6766 noticias, de las cuales 631 abordaron acontecimientos que involucran a jóvenes y a adolescentes. Es decir, la cobertura del tema de nuestra investigación ocupó un 9,33\% del hueco informativo del diario.

Los datos demuestran que si bien en términos absolutos la frecuencia de cobertura fue mayor en Río Negro, ambos diarios le dedican un porcentaje similar de su hueco informativo.

\begin{tabular}{|l|c|c|c|}
\hline \multicolumn{4}{|c|}{ HUECO INFORMATIVO } \\
\hline & TOTAL & PIEZAS /JÓVENES & PORCENTAJE \\
\hline Noticias de la Costa & 3.337 & 332 & $9,95 \%$ \\
\hline Río Negro & 6.766 & 631 & $9,33 \%$ \\
\hline
\end{tabular}

Tabla 1 | Hueco informativo sobre jóvenes y adolescentes en los diarios Noticias de la Costa y Río Negro (Fuente: elaboración propia)

\section{Los temas de la agenda mediática sobre la cuestión juvenil}

Cuando abordamos los temas de las noticias, desde la propuesta de Donald Shaw (citado en Aruguete, 2009), hacemos referencia a las categorías en torno a las cuales se involucran y se agrupan los acontecimientos en el tratamiento periodístico. Dominique Pasquier (citado en Aruguete, 2009), por su parte, establece la distinción entre eventos (acontecimientos puntuales limitados en el tiempo) y temas (hechos que están ligados entre sí y que, por ello, entran en una categoría genérica).

Hemos cuantificado las piezas informativas que, por los hechos que relatan, hacen referencia a un tema con el fin de conocer la relevancia que los diarios dan a jóvenes y a adolescentes, y el tipo de tratamiento que les otorgan. El análisis de la cantidad de piezas destinadas a ciertos temas y tópicos particulares resulta trascendente para 
conocer los tipos de asuntos con los cuales se los/las vincula, la heterogeneidad o la homogeneidad de los temas y las modalidades o los encuadres resaltados en las coberturas noticiosas.

En relación con los temas y los tópicos con los cuales se vincula a jóvenes y a adolescentes en las noticias abordadas a partir de una aproximación exploratoria de los diarios elaboramos la siguiente lista de asuntos:

\section{a) Actividades recreativas}

1- Deportes

2- Actividades en espacios públicos

3- Actividades en instituciones culturales

4- Arte

5- Otros

\section{b) Violencia}

1- Violencia entre jóvenes (robo, choque, asalto, asesinato, etc.)

2- Violencia de jóvenes hacia otras personas (robo, choque, asalto, asesinato, peleas, etc.)

3- Violencia de otras personas hacia los jóvenes (robo, choque, asalto, asesinato, peleas, etc.)

4- Justicia, reclamos y resoluciones judiciales (robo, choque, asalto, asesinato, peleas, etc.)

5- Otros

c) Salud

1- Embarazo

2- Droga, alcoholismo

3- Enfermedades de transmisión sexual

4- Suicidio

5- Otros

\section{d) Educación y participación}

1- Participación vinculada con instituciones educativas

2- Éxitos y mérito escolar

3- Formación y empleo

4- Otros

\section{e) Política y participación}

1- Partidos políticos

2- Movilizaciones y marchas

3- Derechos humanos

4- Políticas públicas (empleo, seguridad, vivienda, otras)

5- ONG

6- Otros 


\section{f) Género}

1- Femicidio

2- Violencia hacia las mujeres

3- Justicia, reclamos y resoluciones judiciales

4- Otros

Pero ¿cuáles fueron los temas que predominaron en las noticias de los diarios analizados en las que aparecen involucrados jóvenes y adolescentes?

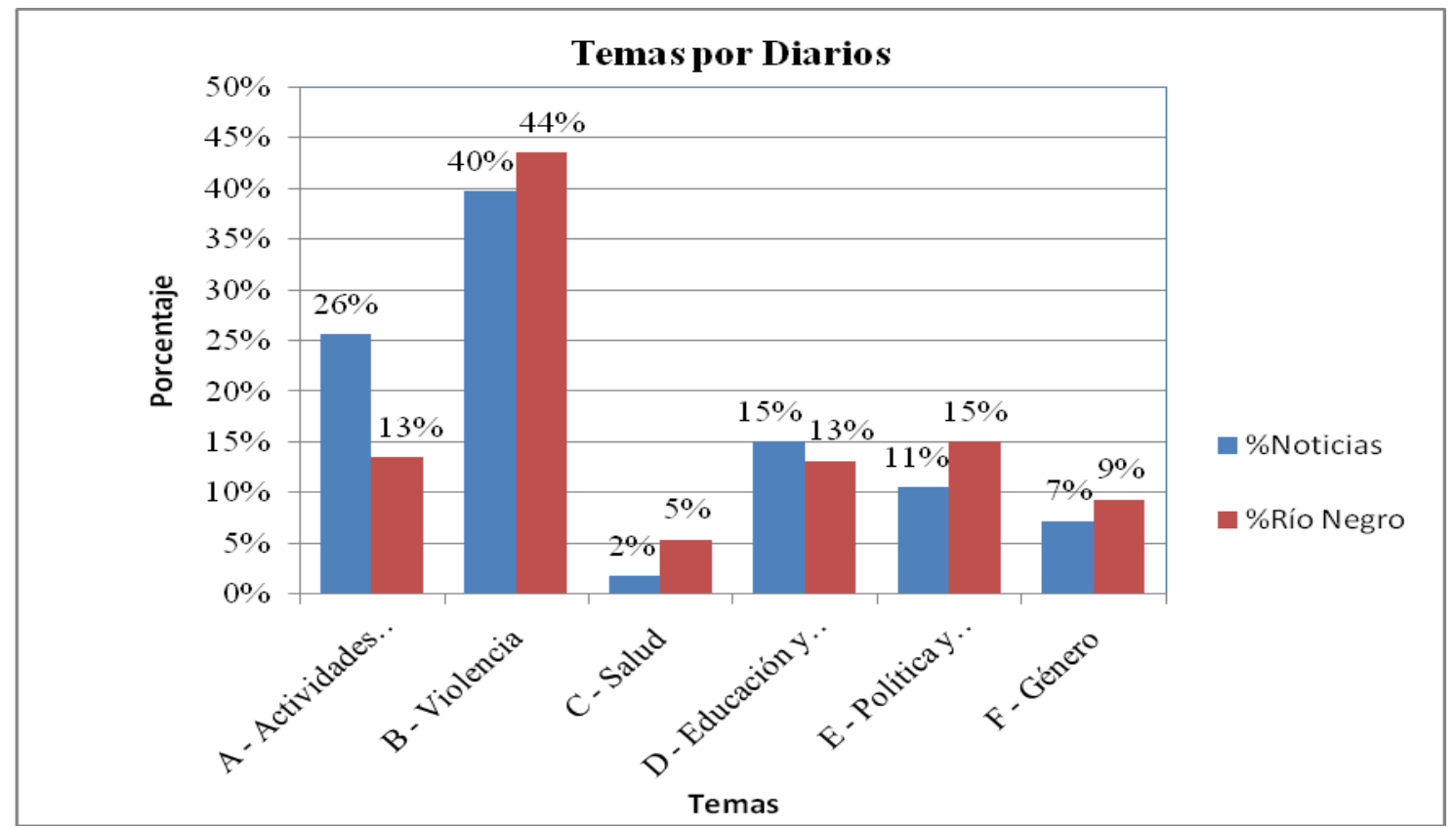

Gráfico 1 | Temas principales de las noticias de ambos diarios en la que aparecen jóvenes y adolescentes involucrados (Fuente: elaboración propia)

Como muestra el gráfico 1, el tema que con mayor frecuencia cubren los dos diarios analizados es violencia, que ocupa el primer lugar, con 132 piezas periodísticas en el diario Noticias de la Costa (40\%) y con 275 en el diario Río Negro (44\%). Es decir, casi la mitad del espacio que ambos diarios dedican para visibilizar a jóvenes y a adolescentes refieren a hechos violentos y, principalmente, delictivos: de las 963 noticias recopiladas donde jóvenes y adolescentes aparecen como actores (protagonistas o secundarios), 407 relatan situaciones delictivas donde se los asocia con robos, asaltos, peleas, choques o asesinatos. Como actores de las noticias, jóvenes y adolescentes cobran visibilidad con el sesgo de la violencia y la estigmatización. 
Muy por debajo de violencia aparecen los demás temas: actividades recreativas, educación y participación, política y participación, género y salud. Se observan, no obstante, algunos matices entre ambos diarios: mientras que Río Negro le otorga un mayor espacio al tema salud, Noticias de la Costa le otorga mayor espacio al tema actividades recreativas.

\section{Coberturas noticiosas sobre ueducación y participación»}

En este apartado, se presentan algunas características del tratamiento realizado por los diarios sobre acontecimientos en los que aparecen involucrados jóvenes y adolescentes como participantes de instituciones y de políticas educativas. Se identifican actores principales de las noticias, fuentes y encuadres utilizados por dichos medios.

Del total de noticias recopiladas, un 14\% (133 piezas periodísticas) narra acontecimientos donde jóvenes y adolescentes se encuentran vinculados con instituciones y con políticas educativas. La cobertura de este tipo de noticias presenta una importante diferencia entre quienes cumplen el rol de fuentes y quienes son mostrados como actores / protagonistas de las noticias.

En los procesos de construcción noticiosa, las fuentes son actores fundamentales de interacción con los medios ya que proporcionan información y brindan acceso a los acontecimientos que se narran (Rost, 2009). Pero no todos los actores que se constituyen en fuentes informativas tienen la misma capacidad de interacción con los medios. Los más cercanos al poder suelen acceder a la agenda mediática con mayor estabilidad; en cambio, los más vulnerables, deslegitimados o sin amparo institucional son objeto de una exposición descuidada (Aruguete, 2010).

En la construcción de las noticias también se pone en juego la visibilidad de los protagonistas, es decir, cómo los actores que intervienen en los acontecimientos narrados se hacen visibles para el público. Los protagonistas son los individuos o los grupos de individuos a quienes el medio enfoca, retrata o menciona. Son los que salen en las fotografías, los que son filmados o simplemente mencionados en los medios como actores de la realidad. Los protagonistas son los personajes que se hacen visibles para el público aunque no necesariamente su punto de vista o su voz sean tenidos en cuenta. 
Dentro del corpus definido como «Educación y participación», en el 38\% de las piezas periodísticas (50 en total) aparecen jóvenes y adolescentes como actores principales de los acontecimientos que se narran. Otros actores importantes en este corpus de noticias son: la escuela, la institución educativa o los directivos, con un 17\%; funcionarios o políticos, con un 10\%; vecinos y familiares, con un $8 \%$; y organismos públicos, con un $7,5 \%$, entre otros.

Al identificar las fuentes dentro del mismo conjunto de noticias se invierte el orden de relevancia: las principales fuentes utilizadas por los diarios estudiados son los organismos y los funcionarios públicos (25\%). Luego, se tuvo en cuenta la voz de los directivos de las escuelas (22\%). En tercer lugar, y muy por debajo de las anteriores fuentes, se cita la voz de jóvenes y de adolescentes (10\%), preferentemente en noticias de interés humano orientadas hacia el éxito escolar individual. Solo en cuatro noticias sobre reclamos por falta de infraestructura y de servicios en las escuelas se cita a jóvenes y a adolescentes. Cabe destacar que un alto porcentaje de noticias no cita fuente alguna (24\%).

Las fuentes informativas proveen, generalmente, el aspecto ideológico de los contenidos noticiosos. Los encuadres o las perspectivas enfatizados en las noticias «son la huella del ejercicio del poder en los textos» (Aruguete, 2010, p. 4): «registran la identidad de actores o de intereses que compiten por dominar el texto» (Entman, 1993, p. 55).

En síntesis, las coberturas noticiosas de acontecimientos sobre temas de «Educación y participación» que involucran a jóvenes y a adolescentes en los diarios estudiados se caracterizan por desatender sus voces como fuentes informativas y por desplazarlos del lugar de enunciación; jóvenes y adolescentes son vistos, mostrados en las noticias, pero enunciados y comprendidos desde el lugar de las instituciones (principalmente, de los directivos o los funcionarios públicos) quienes se posicionan como portadores de la voz autorizada para interpretar los hechos y sus protagonistas. 


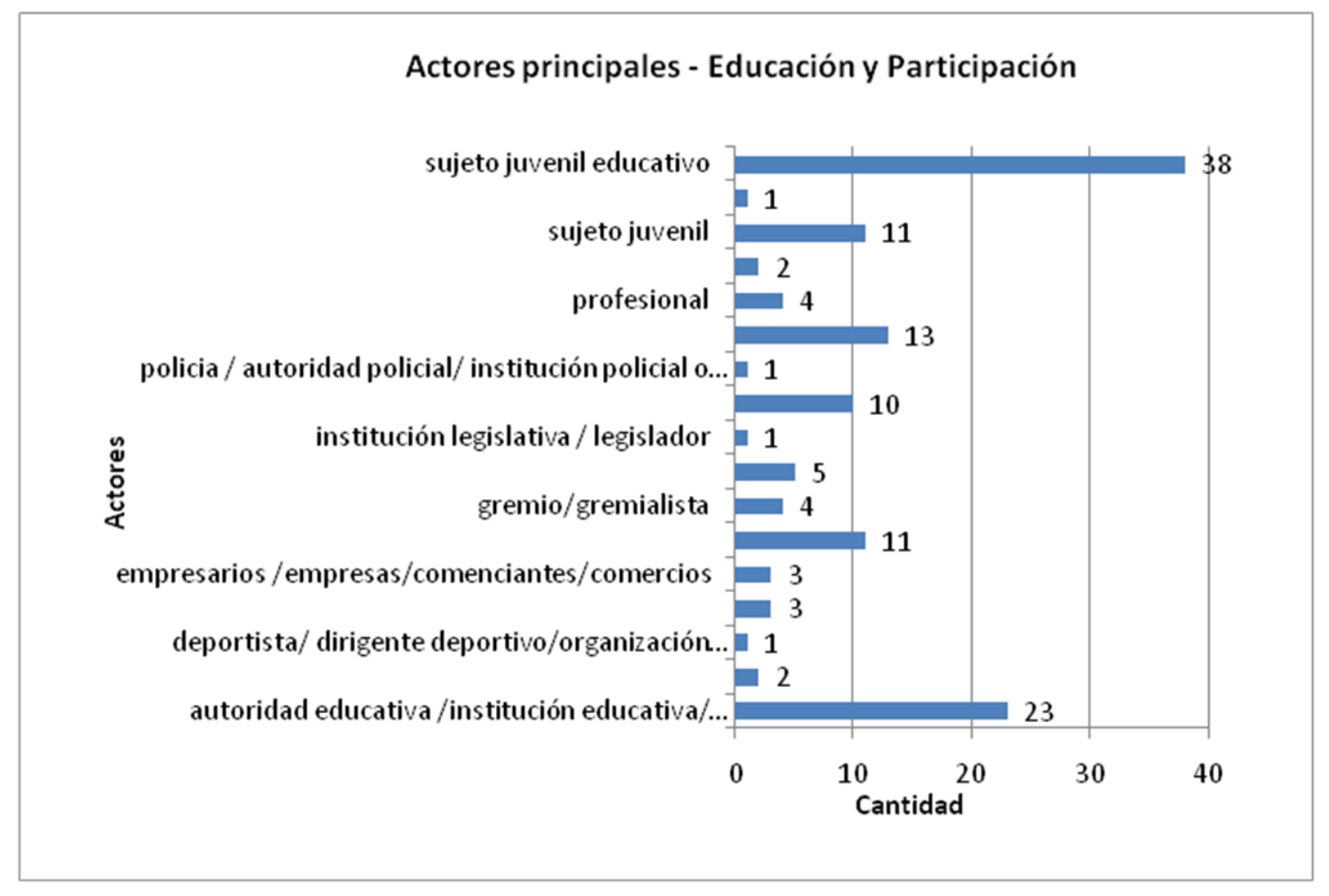

Gráfico 2 | Actores principales de las noticias sobre Educación y participación, de ambos diarios, en las que aparecen jóvenes y adolescentes involucrados (Fuente: elaboración propia)

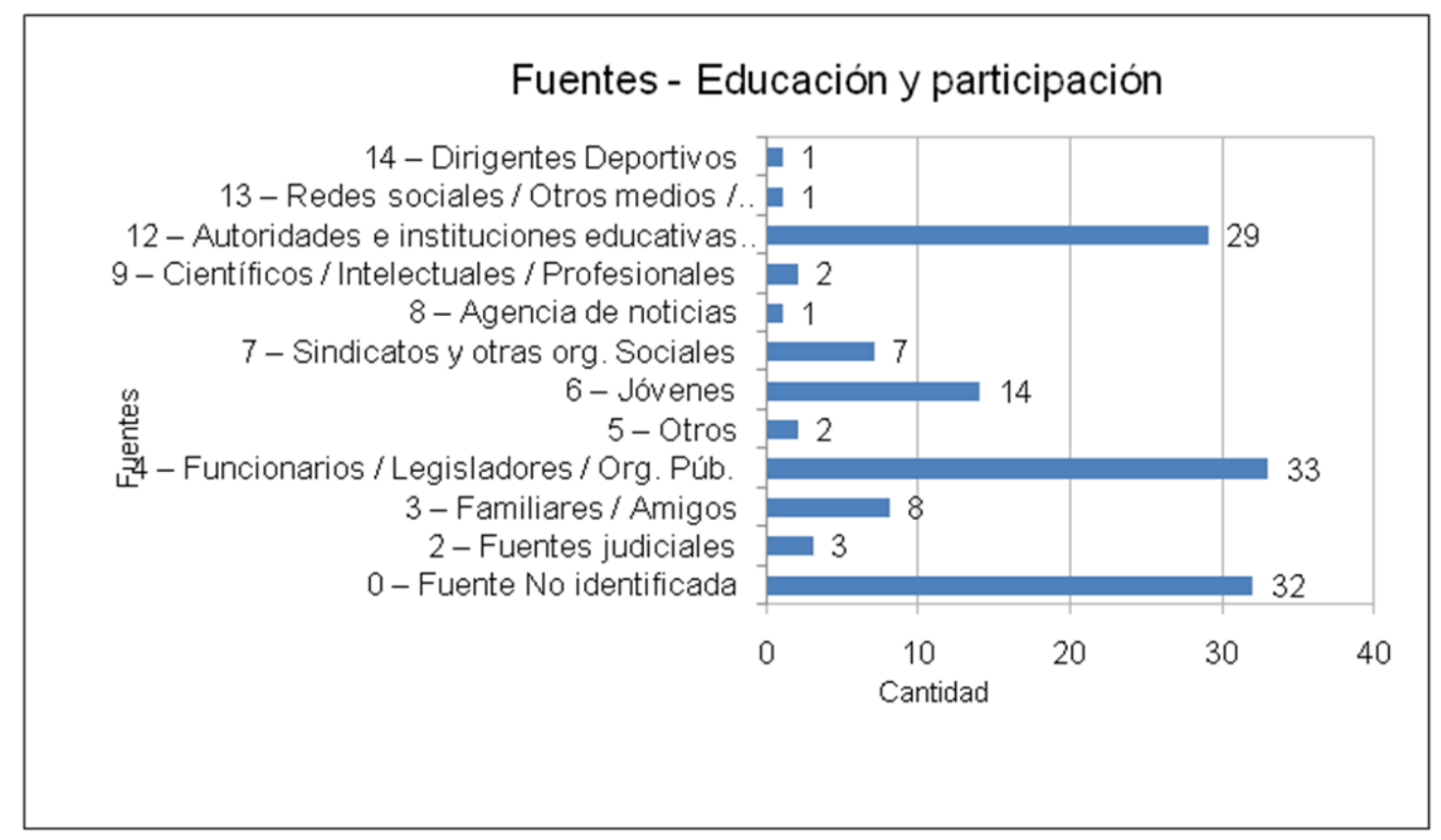

Gráfico 3 | Fuentes principales utilizadas en las noticias sobre Educación y participación, de ambos diarios, en las que aparecen jóvenes y adolescentes involucrados (Fuente: elaboración propia) 
Para analizar los encuadres con los cuales los medios presentaron las noticias sobre educación se partió de la definición de encuadres noticiosos de Juan José Igartua (2006), quien los conceptualiza como «constructos o variables latentes, no observables ni medibles directamente, sino que emergen a partir de una serie de indicadores manifiestos» (p. 157). Se tuvieron en cuenta algunas variables críticas para identificar dichos encuadres: tipo de acciones que se destacan en la noticia, modo en el que se presenta a los protagonistas de la información —entendiendo que ello puede generar en el lector una atribución de responsabilidades-, causas de las acciones y agentes que las motivan, fuentes utilizadas y modo en el que se relatan los hechos.

Los encuadres identificados en el corpus de noticias sobre Educación fueron los siguientes: atribución de responsabilidad (47\%), promoción de instituciones, organismos y programas (26\%), interés humano con énfasis en el éxito escolar a nivel individual (10\%) y grupal (8\%), análisis institucional y social de problemáticas educativas (4\%) y otros $(5 \%))^{2}$

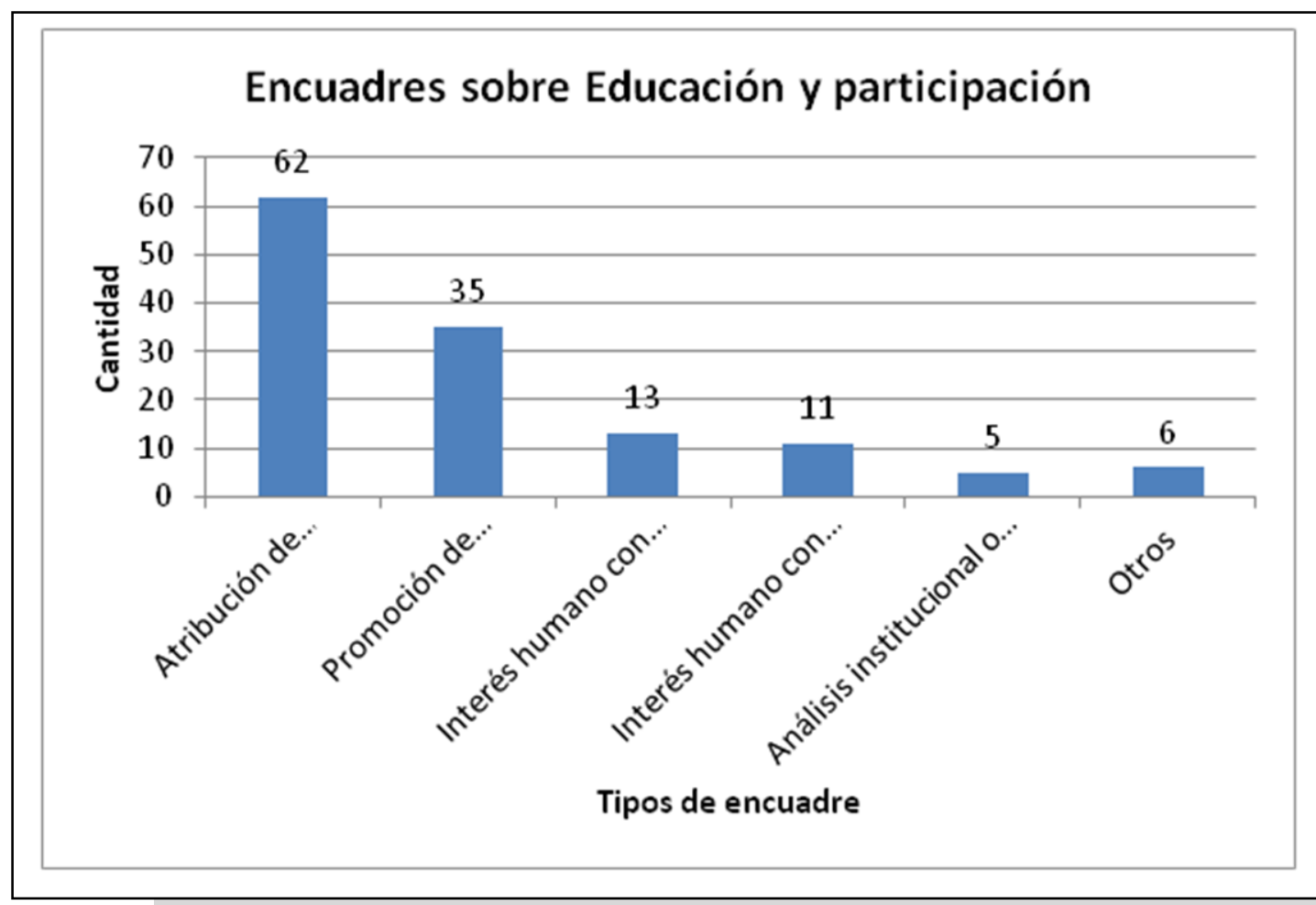

Gráfico 4 | Encuadres utilizados en las noticias sobre Educación y participación, de ambos diarios, en las que aparecen jóvenes y adolescentes involucrados (Fuente: elaboración propia) 
En su gran mayoría, las noticias sobre Educación se definen bajo un encuadre de atribución de responsabilidad (50 noticias). El conjunto de noticias construidas desde este encuadre informan, en forma episódica, acerca de distintos reclamos por parte de la comunidad educativa en escuelas de Nivel Medio (de distintas regiones de Río Negro y de Neuquén) frente a la falta de infraestructura o a la deficiencia de algún tipo de servicio que obstaculiza el desarrollo adecuado de las clases. Por lo general, la noticia describe una situación puntual en una escuela y a un actor particular como principal perjudicado por la situación. En este tipo de noticias, frecuentemente se muestra a jóvenes y a adolescentes, en su carácter de estudiantes, como principales afectados. Sin embargo, a pesar de ser vistos como principales afectados, las fuentes más citadas en la narración de estos acontecimientos noticiosos son los directores y las directoras de las escuelas o los funcionarios y las funcionarias del Ministerio de Educación. El reclamo tiende a orientarse hacia la responsabilidad del Estado pero el tratamiento de los asuntos y la referencia particular a las autoridades del gobierno provincial y de los consejos municipales sugiere considerar responsabilidades individuales.

Por debajo de este enfoque mediático, otro grupo de noticias sobre temas educativos se define bajo el encuadre de la promoción de actividades por parte de distintas instituciones, organismos y programas educativos. También en este grupo de enunciados se describen eventos puntuales (capacitaciones, talleres, proyectos escolares, entre otros) llevados a cabo por las escuelas de la región norpatagónica o por distintos organismos públicos de Río Negro y de Neuquén, mientras que los actores particulares - generalmente jóvenes y adolescentes- son mostrados como principales beneficiarios de la actividad. En este tipo de noticias, las instituciones educativas o los organismos públicos aparecen como actores principales, en tanto impulsan proyectos y tareas para beneficiar a estudiantes de la comunidad.

Un tercer grupo de noticias organiza la información bajo el encuadre del interés humano, con predominio de notas de color o de historias de vida. Estas piezas periodísticas abordan distintos eventos o desempeños escolares de jóvenes y de adolescentes desde un punto de vista que enfatiza los éxitos o los logros del principal actor de la noticia, ya sea individual o grupal. Generalmente, este encuadre tiende a mostrar el desempeño individual de un alumno (10\%) o de un grupo de alumnos (8\%) desde un ángulo emocional, particular y, en algunos casos, dramático. Desde este encuadre noticioso, la recurrencia a estudiantes ejemplares y el uso de historias de vida —claramente más excitantes para el ojo público - genera una identificación en la audiencia que reacciona ante los «problemas» desde un enfoque moral e individual (Aruguete, 2013). 


\section{Algunas conclusiones}

Los primeros resultados de nuestra investigación nos permiten afirmar que el protagonismo juvenil tiene poca relevancia en la producción noticiosa de los diarios impresos de la región y presenta una fuerte homogeneidad temática. Los jóvenes aparecen poco en las noticias y lo hacen, principalmente, involucrados en acontecimientos delictivos (como víctimas, como victimarios o actuando con violencia unos contra otros) en desmedro de su aparición en otros tipos de acontecimientos.

Las coberturas noticiosas se caracterizan por desatender como fuentes informativas las voces de jóvenes y de adolescentes, que tienden a ser desplazadas del lugar de enunciación al lugar de la visualidad. En las noticias sobre Educación, jóvenes y adolescentes son vistos, mostrados, enunciados, desde las voces de los directivos o de los funcionarios, como los portadores de la voz autorizada para presentar y para representarlos.

Finalmente, se han propuesto, desde un abordaje exploratorio, algunas características generales de los encuadres noticiosos utilizados en la construcción de noticias sobre acontecimientos educativos que involucran a jóvenes y a adolescentes como actores de las noticias. Dichos encuadres proveen de una herramienta conceptual y operativa para analizar el tipo de cobertura que tiene la participación juvenil en instituciones y en actividades del sistema educativo en los medios analizados.

Los encuadres funcionan para dar mayor relevancia en los textos a algunos conceptos y para soslayar otros. Como principios organizadores socialmente compartidos, los encuadres identificados en nuestro estudio son utilizados por los productores de noticias de los diarios analizados, quienes participan activamente en la producción social de sentidos, desde una posición dominante en la región norpatagónica, en tanto trabajadores de dichos medios.

$\mathrm{Al}$ encuadrar los acontecimientos noticiosos, los medios actúan en la producción de los problemas sociales, de sus causas o de las fuerzas que los crean, y sugieren soluciones, ofreciendo y justificando un tratamiento y prediciendo sus resultados (Entman, 1993). En síntesis, participan activamente afianzando criterios de focalización que inciden en la definición y en la aceptación de políticas sociales y educativas configuradoras de sujetos juveniles. 


\section{Referencias}

AGUILERA, O. (2012). La construcción cultural de la juventud: políticas de visibilidad y emergencias identitarias en la producción cultural chilena [ponencia]. VIII Conferencia Internacional de la Red Latinoamericana y del Caribe y Reunión Regional Anual. Venezuela, Universidad Metropolitana. Recuperado de http://docplayer.es/17890937-Titulo-la-construccion-cultural-de-lajuventud-politicas-de-visibilidad-y-emergencias-identitarias-en-laproduccion-cultural-chilena.html

AMADEO, B. (2008). «Framing: Teoría para armar». En M. T., Baquerín de Riccitelli (Ed.). Los medios ¿aliados o enemigos del público? (pp. 183281). Buenos Aires, Argentina: EDUCA.

ARUGUETE, N. (2013). La narración del espectáculo político: pensar la relación entre sistema de medios y poder político. Austral Comunicación, 2(2), 205-215. Recuperado de http://www.austral.edu.ar/ojs/index.php/australcomunicacion/article /view/72

ARUGUETE, N. (2011). Framing. La perspectiva de las noticias. La Trama de la Comunicación, vol. 15, 67-80. Recuperado de http://www.fcpolit.unr.edu.ar/wp-content/uploads/Framing.-Laperspectiva-de-las-noticias.pdf

ARUGUETE, N. (2010). Poder y comunicación. Una vulneración al derecho a acceder a la agenda de los medios. Diálogos de la Comunicación, 1(82), 1-8. Recuperado de https://dialnet.unirioja.es/descarga/articulo/3728213.pdf

ARUGUETE, N. (2009). Estableciendo la agenda. Los orígenes y la evolución de la teoría de la agenda setting. Ecos de la comunicación, 2(2), 11-38. Recuperado de

http://bibliotecadigital.uca.edu.ar/repositorio/revistas/estableciendola-agenda.pdf 
ARUGUETE, N. y AMADEO, B. (2012). Encuadrando el delito. Pánico moral en los periódicos argentinos. América Latina Hoy, (62), 177-196. Recuperado de http://revistas.usal.es/index.php/1130$2887 /$ article/view/9350

EDELMAN, M. (1991). La construcción del espectáculo político. Buenos Aires, Argentina: Manantial.

ENTMAN, R. (1993). Framing: Toward a Clarification of a Fractured Paradigm. Journal of Communication, 43(3), 51-58.

IGARTUA, J. J. (2006). Métodos cuantitativos de investigación en comunicación. Barcelona, España: Bosch.

McCOMBS, M. (2006). Estableciendo la agenda. El impacto de los medios en la opinión pública y el conocimiento. Barcelona, España: Paidós.

ROST, A. (2009). Desde los hechos hasta la noticia. Los actores que intervienen en la construcción de la actualidad. Revista de la Facultad, 1(15). Recuperado de

https://www.academia.edu/1535022/Desde_los_hechos_hasta_la_notici a._Los_actores_que_intervienen_en_la_construcci\%CC3\%B3n_de_la_actual idad

SPECTOR, M. y KITSUSE, J. [1987 (1977)]. Constructing social problems. Nueva York, Estados Unidos: Aldine.

TUÑóN, I. (2002). La formación de una agenda pública. El caso de los jóvenes que no estudian ni trabajan [ponencia]. Jornadas de la licenciatura en Ciencias de la Comunicación. Buenos Aires, Argentina: Universidad de Buenos Aires. 
1 El proyecto, titulado «Políticas de visibilidad y agendas de lo juvenil en Viedma» (04/V095), se desarrolla en el CURZA, de la Universidad Nacional del Comahue, y está inscripto en el Centro Interdisciplinario de Estudios sobre Derechos, Inclusión y Sociedad (CIEDIS), Sede Atlántica, de la Universidad Nacional de Río Negro.

2 Actualmente, el equipo del proyecto se encuentra en una fase inicial de análisis de los encuadres noticiosos identificados en el corpus seleccionado para la investigación. En este trabajo se presentan algunos resultados preliminares. 